\title{
Studies of The Mechanism of Polyvinyl Alcohol Adsorption on The Calcite/Water Interface in The Presence of Sodium Oleate
}

\author{
N.S. LABIDI ${ }^{* 1}$ and A. DJEBAILI ${ }^{2}$ \\ ${ }^{1}$ Department of chemistry, Faculty of sciences, University of the sciences and technology \\ of Oran (U.S.T.O.MB), BP-1505 Oran El-M'naouer (31000), Algeria \\ ${ }^{2}$ Laboratoire d'Etude des Matériaux Organiques LEMO, Faculté des Sciences- \\ Département de chimie Université de Batna, 05000, Algerie \\ *E-mail: labidi2006@univ-usto.dz,Tel /Fax : (213)41.56.03.00
}

\begin{abstract}
The adsorption behavior of polyvinyl alcohol (PVA) on the $\mathrm{CaCO}_{3} /$ solution interface under the influence of sodium oleate (SOl) interaction was investigated by the adsorbed amount, FTIR spectra, X-Ray diffraction and zeta potential. Effects of solid to liquid ratio and temperature was also examined. Observed increase of the PVA adsorption in presence of the sodium oleate resulted from a polymer-surfactant complex formation. The surfactant also influences on the structure of the adsorbed polymer layers. This effect was proved by adsorption measurements that allow calculation of the thickness of the adsorbed layer of the polymer on the surface of $\mathrm{CaCO}_{3}$ in the presence and the absence of sodium oleate. The interaction between oleate anions and PVA is a physical type (via hydrogen bonding).
\end{abstract}

Key Words: Adsorption; Polyvinyl alcohol (PVA) ; Sodium oleate; Calcite ; Polymerconformation.

\section{INTRODUCTION}

Interaction between polymers and particles surfaces are widespread and of great industrial and technological significance For instance, the flocculation of colloidal particles by the introduction of a polymer into the liquid suspensions is an important solid- liquid separation process in various industrial and technological processes, mineral processing, municipal water and waste water treatments, etc. [1-3]. Adsorption of polymers at the solid-solution interface has profound effects on the flocculation and 
stabilization behavior of colloidal suspensions. For charged polymer-adsorbent systems, mainly strong electrostatic interaction works and influences adsorption according to their charges. For uncharged polymers, only H-bonding and solvation forces are important. Although the adsorption behavior of PVA polymer on solid-liquid interface are well documented in literature, the amount adsorbed is strongly dependent on the molecular weight and the number of acetate groups of PVA, resulting in different adsorption layer thickness. The adsorption force increases with increasing degree of hydrolysis of PVA. The presence of the hydrophobic acetate groups also affects the conformation of polymer chains adsorbed on the particle surface [4-7]. The adsorption mechanisms of PVA on different types of particles are also varied. For example, the amount adsorbed on $\mathrm{TiO}_{2}$ increases with the suspension $\mathrm{pH}$ as the thickness of the double-layer surrounding the $\mathrm{TiO}_{2}$ particle is determined mainly by the molecular weight and the number of the acetate groups of PVA. By contrast, the affinity of PVA and $\mathrm{SiO}_{2}$ particles is strong at low $\mathrm{pH}$, but weak at high $\mathrm{pH}$. That is, the quantity of PVA adsorbed on the silica surface decreases with increasing $\mathrm{pH}$. Since the adsorption of nonionic polymers, such as PVA, is through hydrogen bonding with the silanol group on the silica surface, the adsorption is favorably under low $\mathrm{pH}[8-10]$.

Introduction of a surfactant to a polymer solution-solid system may markedly influence the adsorption properties of the polymer. This problem is very interesting also from practical point of view because of increasing application of both, polymers and surfactant, in mineral processing [11]. Many studies on polymer-surfactant interaction on solid surfaces, was frequently found possible to obtain elevated uptake of one or other of the components. Otsuka and Esumi [12], dealing with a coadsorption study, shows a remarkable increase in uptake of PVP on alumina in the presence of LiDS. A second illustration by Cosgrove et al. [13], concerns the effect of SDS on the adsorption of PEO by silica. PEO adsorbs strongly on silica, and SDS hardly at all. In this case SDS is seen to bring about a progressive thinning of the PEO layer, reaching a limit around the CMC of the surfactant and beyond the CMC the layer thickness increases again, suggesting that SDS micelles are bound by the residually attached PEO chains. Kilau and Voltz. [14] find that the wetting of a hydrophobic surface (coal) by an anionic surfactant is promoted by the addition of the uncharged polymer PEO. Fleming et al. [15], studies on the graphite-PVP-SDS system shown that addition of surfactant leads to an initial increase and then to a decrease in PVP adsorption. Unfortunately literature data concerning such systems polymer-surfactant onto salt-type minerals (such as calcite, dolomite, phosphorite etc..) are scarce.

In the present study, adsorption of polyvinyl alcohol (PVA), with and with out sodium oleate $(\mathrm{SOl})$ onto calcite surface has been investegated in order to elucidate the effects of polymer molecular weight, and the polarity of calcite surface, on the polymer- 
surfactant interaction. In addition the conformation of PVA adsorbed on calcite is also estimated from adsorption denseties.

\section{EXPERIMENTAL}

\subsection{Materials}

The calcite sample used in this study was supplied from a mining company (Djebl Onk- mining complex of phosphate) in Algeria.The sample was air-dried and then sieved to give a $-80+100 \mu \mathrm{m}$ size fraction using ASTM Standard sieves. The chemical composition of the calcite, determined by a Cameca SX-50 electronic microprobe, is is given in Table 1. Mineralogical species of calcite were characterized by X-ray powder diffraction employing Bruker Axs diffractometer using monochromated $\mathrm{Cu}-\mathrm{K} \alpha(\alpha=$ $1.5406 \AA$ ) Fig.1.The specific surface area of calcite measured at $77 \mathrm{~K}$ using the BET $\mathrm{N}_{2}$ method, was found to be $0.40 \mathrm{~m}^{2} / \mathrm{g}$ (via an Micometrics model 2100).

Table 1. Chemical anlyses of Calcite

\begin{tabular}{ccccccc}
\hline Constituants & $\mathrm{CaO}$ & $\mathrm{MgO}$ & $\mathrm{FeO}$ & $\mathrm{SiO}_{2}$ & $\mathrm{CO}_{2}$ & total \\
\hline Pourcentage \% & 52.50 & 0.72 & 0.09 & 0.15 & 46,42 & 99.96 \\
\hline
\end{tabular}

As a nonionic polymer, Polyvinyl alcohol, PVA (Aldrich) with the average molecular weights $(M \mathrm{w})$ of 13,000 and 23,000 (degree of hydrolysis 97.5\%) were used in the study.The polymer was filtered through the cellulose membranes (Millipore) to eliminate inorganic contamination and lower polymer fraction.PVA chains contain acetate groups which did not undergo hydrolysis in the production process of polyvinyl alcohol from polyvinyl acetate. PVA 13,000 and PVA 23,000 used in the study have the degree of hydrolysis equal to $97.5 \%$. Depending on the degree of hydrolysis, the PVA contains $2.5 \%$ of acetate groups $\left(-\mathrm{C}_{4} \mathrm{O}_{2} \mathrm{H}_{6}-\right)$. The polymer used may be considered as a copolymer of vinyl alcohol and vinyl acetateaccording to the following scheme:

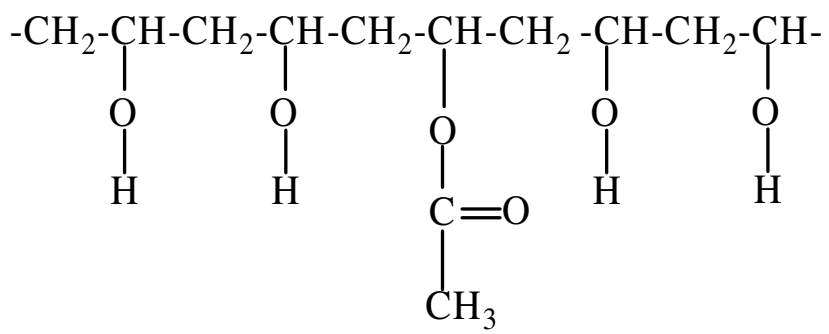


The anionic surfactant used in these studies was pure sodium oleate $\mathrm{C}_{18} \mathrm{H}_{33} \mathrm{NaO}_{2}(\mathrm{SOl}$, 99\%) provided by the Sigma Chemical Company.

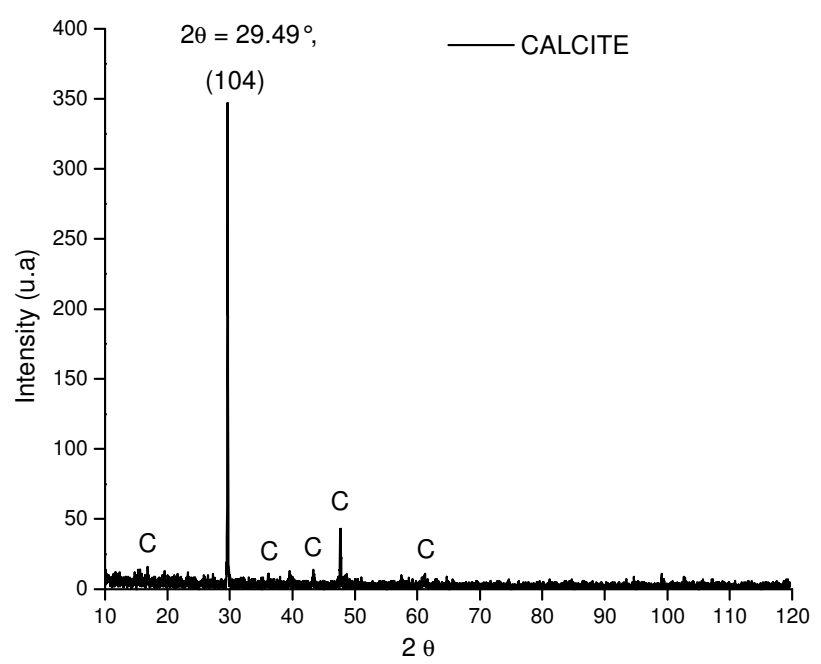

Fig. 1. X-Ray diffraction patterns of calcite (In agreement with JCPDS, cardN ${ }^{\circ}-05-0586$ ).

\subsection{Method}

Adsorption experiments were carried out by the direct contact method which involves shaking of a $100 \mathrm{ml}$ PVA solution of definite concentration containing $1 \mathrm{~g}$ of calcite $\left(\mathrm{S} / \mathrm{L}=0.01\right.$, the ionic strength fixed at $3 \times 10^{-3} \mathrm{M}$ using $\left.\mathrm{KNO}_{3}, \mathrm{pH}=7\right)$. The suspension was shaken for $1 \mathrm{~h}$ to be sure that the equilibrium is reached, After shaking, the suspensions were centrifuged at $3000 \mathrm{rpm}$ for $5 \mathrm{~min}$ and the residual concentration of PVA in the supernatant was estimated by the PVA boric acid iodide complex method [16]. The amount of residual concentration of PVA was calculated with the help of a calibration plot obtained by measuring the absorbance of the yellow red colored formed complex spectrophotometrically at $682 \mathrm{~nm}$ using UV-vis Janway6300 spectrophotometer. The adsorption density and The thickness of PVA layer adsorbed on calcite were calculated using equations (1) and (2), respectively [17,18].

$\Gamma=\frac{\left(C_{i}-C_{r}\right) x V}{m x S_{A}}$

$\delta=\frac{\Gamma}{\rho}$

Where, $\Gamma$ is the adsorption density $\left(\mathrm{mg} / \mathrm{m}^{2}\right), \mathrm{C}_{\mathrm{i}}$ and $\mathrm{C}_{\mathrm{r}}$ are the initial and equilibrium concentrations ( $\mathrm{mg} / \mathrm{ml}$ ) of PVA, respectively, $\mathrm{V}$ is the volume of suspensions (l) and (m) 
the amount of adsorbent in $\mathrm{g} . \mathrm{S}_{\mathrm{A}}$ is the specific surface area of calcite particles (calcite $0.40 \mathrm{~m}^{2} / \mathrm{g}$ ). $\delta$ is the adsorbed layer thickness $(\mathrm{m})$ and $\rho$ is PVA density, $\mathrm{g} / \mathrm{m}^{3}$.

\section{- Effect of Sodium oleate on PVA adsorption}

In these experiments, the sodium oleate concentration was kept constant, whereas that of PVA was varied. The dispersions were left rolling for $1 \mathrm{~h}$ and then centrifuged at $10000 \mathrm{rpm}$ for $15 \mathrm{~min}$. The supernatant liquid was then analysed for both PVA and sodium oleate using the methods described above.

\subsection{Zeta Potential Measurements}

In the zeta potential measurement tests, $1 \mathrm{~g}$ of $-80+120 \mu \mathrm{m}$ mineral samples was added into a $250 \mathrm{ml}$ beaker in which $100 \mathrm{ml}^{-3} 0^{-3} \mathrm{M} \mathrm{KNO}_{3}$ solutions were added. The suspension was conditioned for 3 min during which the $\mathrm{pH}$ was adjusted, followed by 10 min of conditioning after adding the appropriate reagents. It was then allowed to settle for $5 \mathrm{~min}$, and about $10 \mathrm{ml}$ of the supernatant was transferred into a standard cuvette for zeta potential measurement using a Micromertrics Zeta Potential Analyzer. Solution temperature was maintained at $25{ }^{\circ} \mathrm{C}$. Ten measurements were taken and the average was reported as the measured zeta potential $[19,20]$.

\subsection{FT-IR Measurements}

FT-IR measurements were recoded on a JASCO 460 FT-IR spectrometer in the region of 400-4000 cm-1 supplied with OMNIC software. The tablets were prepared by grinding $2 \mathrm{mg}$ of the solid sample with $50 \mathrm{mg}$ of $\mathrm{KBr}$. Before every analysis, the background was collected and subtracted from the spectrum of the sample. Two hundred scans at a resolution of $4 \mathrm{~cm}^{-1}$ were recorded for each sample.

\section{RESULTS AND DISCUSSION}

\subsection{Zeta potential measurements}

These measurements indicate charge properties of calcite particles and in turn can suggest what can adsorb, penetrate, and adhere. Fig. 2 displays the zeta potential of calcite in absence and presence of polymer PVA as a function of $\mathrm{pH}$. It is clear that in distilled water the calcite had, an isoelectric point at about 9. Above it, the surface charge is positive.The presence of PVA does not alter the surface potential of calcite.However, a compression in the electrical double layer was observed. After conditionnig with sodium oleate, calcite became negatively charged with a minimum at $\mathrm{pH}=8-10$, indicating that the maxium sodium oleate occured in this $\mathrm{pH}$ range. 
The results indicate that the surface sites remain accessible to potential determining $\mathrm{H}^{+}$ and $\mathrm{OH}^{-}$and the IEP remains unchanged during PVA adsorption.This implys that the polymer does not alter the surface potential. It can be considered, that the decrease in zeta potential relating to adsorption of polymer is not due to a decrease in charge and surface potential, but rather to a shift of the shear plane.The changes of the zeta potential produced by the adsorption of substances with high molecular weight are resulted from blocking of the active sites on the minerals' surface and from the shift of the shear plane as other investigators asserted [21,22].

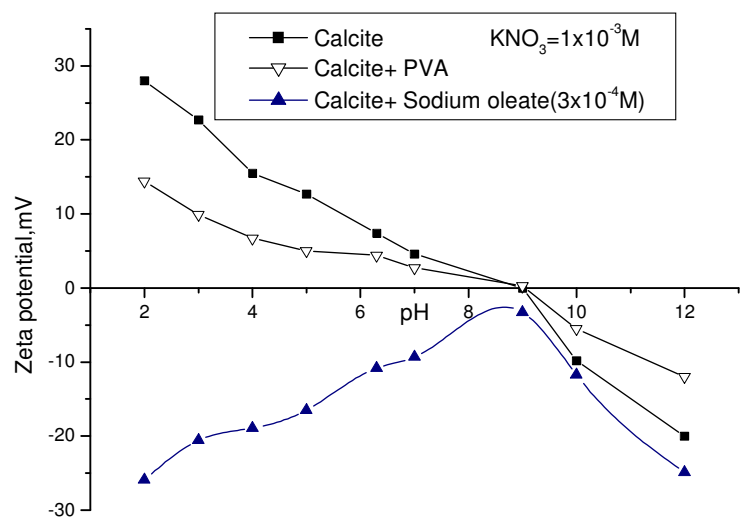

Fig.2. Zeta potential of calcite in absence and presence of PVAand SOl.

\subsection{Adsorption isotherm}

Fig. 3 presents adsorption isotherms obtained for pure solutions of PVA of molecular weights $13,000-23,000$ at constant $\mathrm{pH}$ of 7 and temperature of $25^{\circ} \mathrm{C}$. One can see that an increase of molecular weight of PVA gives distinct increase of the polymer adsorption. This increase is produced by higher affinity of big macromolecules, having more functional groups, than smaller ones to the surface of the solid, as well as appearance of various structures during adsorption of such chains at the solid-solution interface. That is because bonding of the macromolecule with the surface of the solid runs by the number of all existing segments presented in the macromolecule. According to this number of segments of the polymer chain, that interacts with the surface of the solid may be the same for different molecular weights, while total adsorbed amount of the polymer will be greater for the higher molecular weight one [23,24]. We can see that the adsorption isotherms shown in Figures are S-shaped, which suggests a physical adsorption of PVA onto the calcite surface.The adsorption is due to the formation of hydrogen bonding between the calcite surface from one side and $\mathrm{OH}^{-}$polymer functional group from the other side. 


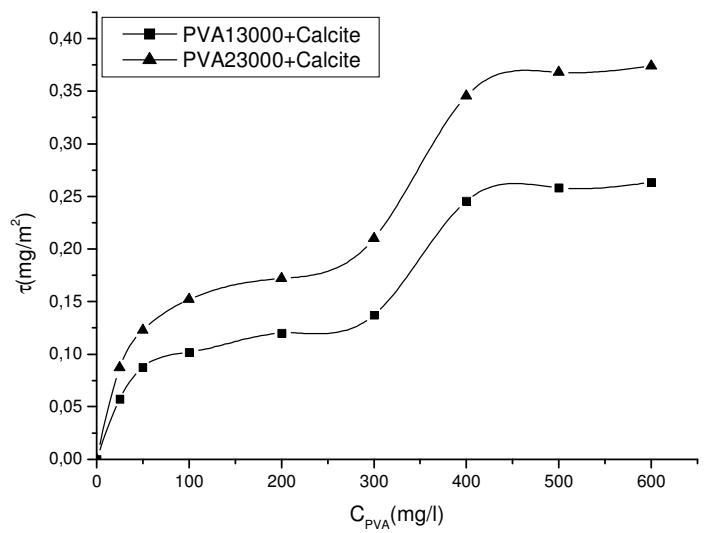

Fig. 3. Adsorption isotherm of PVA of various molecular weights on the surface of Calcite $\left(\mathrm{T}=25^{\circ} \mathrm{C}, \mathrm{pH}=7, \mathrm{C}_{\mathrm{KNO} 3}=10^{-3} \mathrm{M}\right)$.

Fig. 4 illustrates the influence of the sodium oleate on the magnitude of PVA adsorption in the systems studied. As can be seen, the adsorption of PVA on the surface of $\mathrm{CaCO}_{3}$ increases in the presence of sodium oleate.This effect is probably connected with the formation of polymer-surfactant complexes. At the solid interface, the concentration of polymer and surfactant increases in comparison to bulk of the solution. In such place the conditions for PVA-SOl interactions are more favorable and formed complexes follow distinct increase of the polymer adsorption. Another important factor influencing the polymer-surfactant interactions may be caused by changes of the macromolecule conformation in this area. Macromolecules at the solid surface vicinity may increase their linear dimensions (polymer coils may spread due to interaction of the salt-type minerals surface) that increases possibility of their interactions with surfactants.

Fig. 5 shows the influence of the molecular weight on the adsorbed amount of the polymer. The result is that the conformation of the chain with high number of loops and tails should give thicker adsorption layer, so does the increase of the polymer molecular weight. Results presented in Table 2 confirm such hypothesis. Obtained data reveal an increase of thickness of the adsorbed layer of the polymer with increasing of its molecular weight. These results are similar to those previously reported by Chibowski et al (2000-2005) for PVA - Alumina and polyacrylic acid (PAA)-Aluimina [25,26]. 


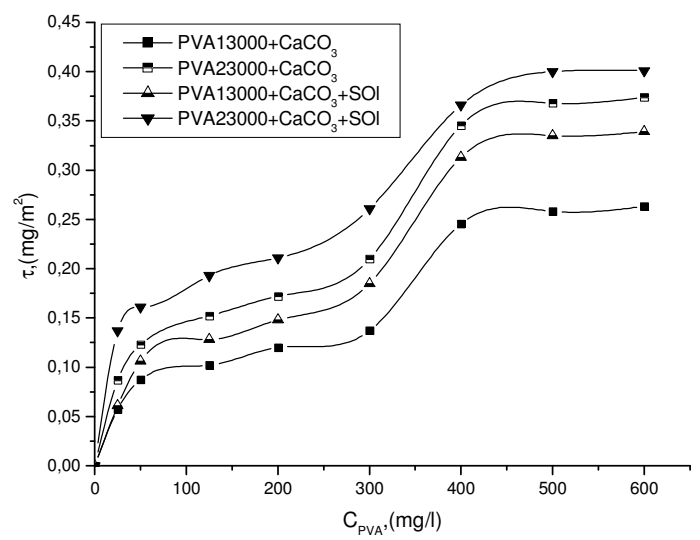

Fig. 4. Adsorption isotherm of PVA of various molecular weights on the surface of $\mathrm{CaCO}_{3}$ with and without sodium oleate $\left(\mathrm{C}_{\mathrm{SOl}}=10^{-3} \mathrm{M}\right)$ as a function of the equilibrium concentration of the polymer in $10^{-3} \mathrm{M} \mathrm{KNO}_{3}$ solution.

Table 2. Thickness of the adsorption layer of the polyvinyl alcohol (PVA) on the surface of $\mathrm{CaCO}_{3}$ from solutions with the mixture of PVA and sodium oleate (SOl).

\begin{tabular}{|c|c|c|c|c|}
\hline$(\boldsymbol{M w}) \mathrm{PVA}$ & $\begin{array}{c}\boldsymbol{\Gamma}\left(\mathbf{m g} / \mathbf{m}^{2}\right) \\
\text { PVA }\end{array}$ & $\begin{array}{c}\boldsymbol{\delta}(\mathbf{n m}) \\
\text { PVA }\end{array}$ & $\begin{array}{c}\boldsymbol{\Gamma}\left(\mathbf{m g} / \mathbf{m}^{2}\right) \\
\text { PVA-SOI }\end{array}$ & $\begin{array}{c}\boldsymbol{\delta}(\mathbf{n m}) \\
\text { PVA-SOl }\end{array}$ \\
\hline 13,000 & 0.25 & 19 & 0.33 & 25 \\
\hline 23,000 & 0.36 & 28 & 0.39 & 30 \\
\hline
\end{tabular}

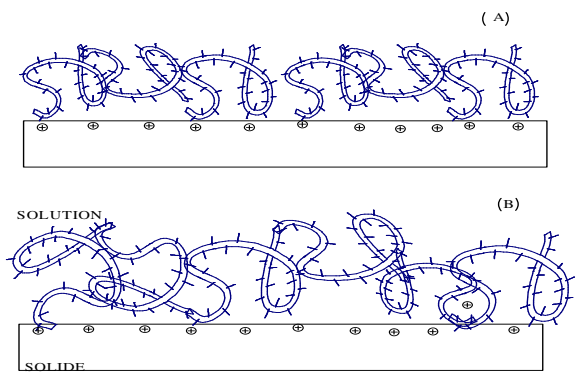

Fig. 5. Polymer-conformation changes with increase of the polymer chain length (molecular weight) on amount of adsorbed polymer : (A) small molecular weight, flat conformation ; (B) big molecular weight, conformation with numerous loops and tails 


\subsection{FTIR Spectral Analysis}

FTIR spectroscopic studies were carried out on calcite, PVA polymer and sodium oleate samples both before and after adsorption. The assignments of the various bands and peaks made in this study are in reasonable agreement with those reported in the literature for similar functional groups.

The FTIR spectra Fig. (6A) show the characteristic absorption bands of calcite $\left(\mathrm{CaCO}_{3}\right)$ located in 1403,875 and $711 \mathrm{~cm}^{-1}$, corresponding to the the asymmetric stretching $\left(v_{3}\right)$; out-of-plane bending $\left(v_{2}\right)$, and the in-plane-bending $\left(v_{4}\right)$ modes of the carbonate $\mathrm{CO}_{3}{ }^{2-}$ ion group are found to be active. The strong bands related to the presence of bound water (v) O-H stretching is around $3400 \mathrm{~cm}^{-1}[27,28]$.

The FTIR spectra of calcite treated with $10^{-3} \mathrm{M}$ Na-oleate Fig.(6B) shows a band at 1648 $\mathrm{cm}^{-1}$. This suggests the formation of a metal complex involving the $\mathrm{COO}^{-}$group (monocoordinated surface calcium oleate $\mathrm{COO}-\mathrm{Ca}^{+}$). The absorption band at $1133 \mathrm{~cm}^{-1}$ is related to $\mathrm{C}-\mathrm{O}$ bonds and the band at $1296 \mathrm{~cm}^{-1}$ is assigned to the bending vibration of $\left(-\mathrm{CH}_{2}-\right)$. Two bands at 2956 and $2853 \mathrm{~cm}^{-1}$ which are characteristic of $(-\mathrm{CH})$ asymmetric and the symmetric stretching respectively. The band at $3475 \mathrm{~cm}^{-1}$ is characteristic of $\mathrm{O}-\mathrm{H}$ stretching. From these results, it can be concluded that oleate anions are chemisorbed on the calcite surface.This agrees with data on the dependence of the $\mathrm{COO}^{-}$frequency on the metal nature $[29,30]$.

The FTIR spectra of calcite, PVA, PVA-adsorbed onto calcite and mixed (SOl-PVA) adsorbed onto calcite are presented in Fig. 7(A), (B) and(C) respectively.

The spectra Fig. 7(A) of PVA used in this study is in good agreement with published IR spectra of PVA. The spectra indicates a wide and intense band due to the presence of hydroxyl groups $(\mathrm{O}-\mathrm{H})$ at $3441 \mathrm{~cm}^{-1}$. The bands corresponding to the $\left(-\mathrm{CH}_{2^{-}}\right)$asymmetric and the symmetric stretching at $2956 \mathrm{~cm}^{-1}$ and $2854 \mathrm{~cm}^{-1}$. The band at $1450 \mathrm{~cm}^{-1}$ can be attributed to $\mathrm{O}-\mathrm{H}$ and $\mathrm{C}-\mathrm{H}$ bending. The band at $941 \mathrm{~cm}^{-1}$ results from an angular deformation outside the plan of $\mathrm{O}-\mathrm{H}$ bond. The absorption peaks at $1112 \mathrm{~cm}^{-1}$ are related to $\mathrm{C}-\mathrm{O}$ stretching. The absorption bands at $1625 \mathrm{~cm}^{-1}$ is due to the symmetric

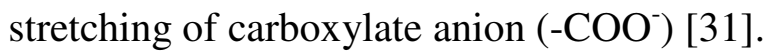

The spectra Fig. 7(B) of PVA-adsorbed onto calcite shows a broad band around $3445 \mathrm{~cm}^{-}$ ${ }^{1}$ is due to the $\mathrm{O}-\mathrm{H}$ vibrations and hence attributable to the existence of surface hydroxyl group (free hydroxyl group) and chemisorbed water (bonded hydroxyl group).The hydroxyl group peak is present in calcite powder without polymer, but the spectra with polymer shows the appearance of this peak. Moreover, the peak intensity of the 
hydrogen-bonded hydroxyl groups is smaller in case of the powder with the polymer than without.This can be attributed to the decrease of surface hydroxyl groups. The extra bands at 1797 and $2250 \mathrm{~cm}^{-1}$ (artefact) corresponds to C-O stretching vibration of ketones, aldehydes, lactones or carboxyl groups. Intensity of these bands decreases after adsorption of PVA onto calcite and therefore the surface functional group is generally neutral or slightly acidic $[32,33]$. This finding is in concurrence with earlier studies, including Pattanayek et al, (2002) on silica-PVA, Besra et al, (2003) on kaolinpolyacrylamide (PAM), and Santhiya et al, (1999) on Alumina-Poly acrylic acid (PAA) and Polyvinyl alcohol (PVA).They showed that the presence of isolated O-H groups on the surface is responsible for the adsorption of polymer molecules by hydrogen bonding [34-36].

The spectra Fig. 7(C) of PVA-sodium oleate adsorbed onto calcite shows absorption peaks at about 3450 and $3546 \mathrm{~cm}^{-1}$ due the presence of hydroxyl groups $(\mathrm{O}-\mathrm{H})$.Two bands at $2956 \mathrm{~cm}^{-1}$ and $2854 \mathrm{~cm}^{-1}$ are corresponding to $(-\mathrm{CH})$ asymmetric and the symmetric stretching.An absorption band at $1637 \mathrm{~cm}^{-1}$ due to the asymmetrical $\mathrm{COO}^{-}$ stretching vibrations is probably associated with $\mathrm{COOH}$ in slight dimerization of oleic acid through partial hydrolysis of the salt. The absorption peaks at $1100 \mathrm{~cm}^{-1}$ are related to $\mathrm{C}-\mathrm{O}$ stretching of $-\mathrm{C}-\mathrm{OH}$ groups of PVA. These results indicating hydrogen bonding interaction between the surfactant $\mathrm{SOl}$ and polymer PVA onto calcite.

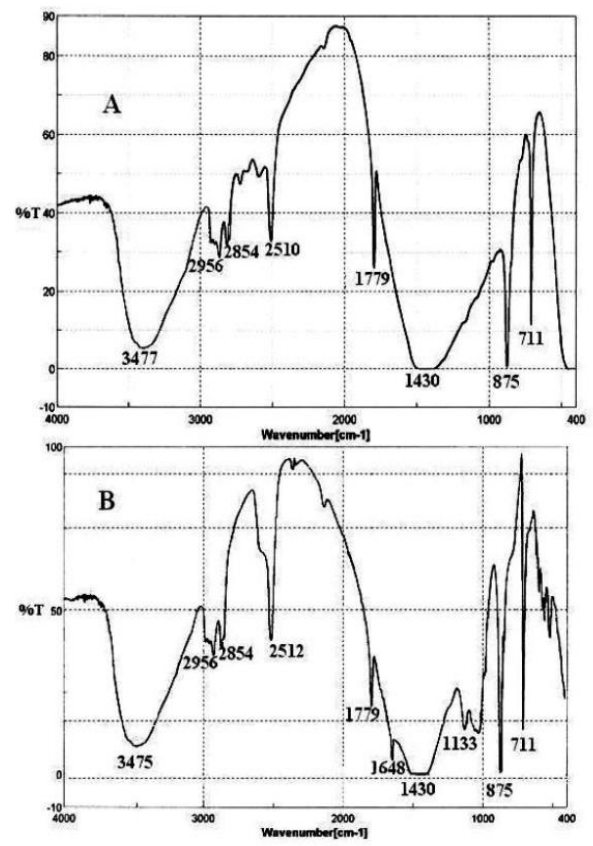

Fig. 6. IR spectra of (A) calcite, (B) calcite-sodium oleate. 


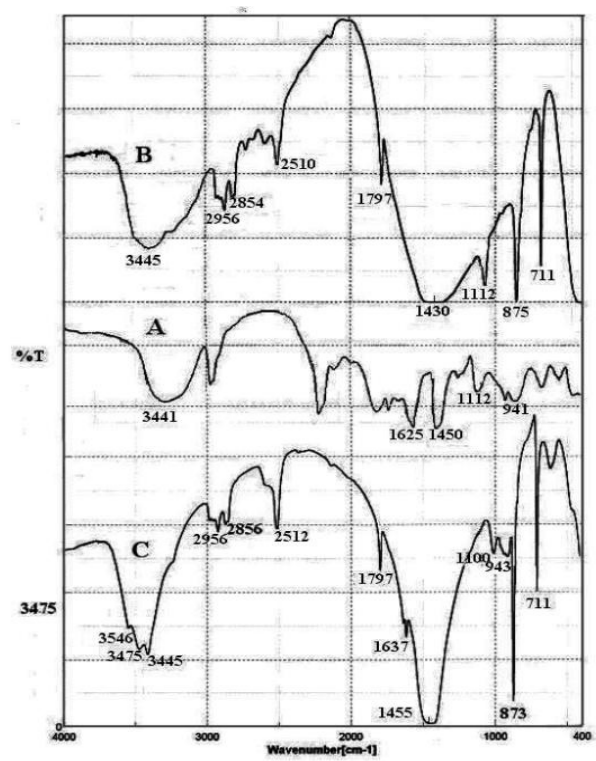

Fig. 7. IR spectra of (A) PVA, (B) PVA-adsorbed onto calcite, (C) (PVA-SOl) adsorbed onto calcite water interface.

\subsection{Mechanism of Adsorption}

Before talking about the mechanism of adsorption the following points need to be taken into consideration to explain the nature of adsorption of long chain surfactant from aqueous solutions first and polymer surfactant in second:

1) In the simple calcite-water system, there are three important factors governing the formation of the calcite surface charge: a) the concentration of potential-determining ions, $\mathrm{Ca}^{2+}$ and $\mathrm{CO}_{3}{ }^{2-}$; $\quad$ b) the $\mathrm{pH}$, on which the concentration of the potentialdetermining anion $\mathrm{CO}_{3}{ }^{2-}$ depends ; $\quad$ c) suspension concentration.In such system the following species are in equilibrium: $\mathrm{Ca}^{2+}, \mathrm{CO}_{3}{ }^{2-} \mathrm{HCO}_{3}^{-}, \mathrm{CaHCO}_{3}{ }^{+}, \mathrm{H}^{+}, \mathrm{OH}^{-} \cdot \mathrm{H}_{2} \mathrm{CO}_{3}$, the charge balance can be expressed by the equation :

$$
\left[\mathrm{H}^{+}\right]+2\left[\mathrm{Ca}^{2+}\right]=\left[\mathrm{HCO}^{-3}\right]+2\left[\mathrm{CO}_{3}^{2-}\right]+\mathrm{OH}^{-}
$$

2) In the approximate $\mathrm{pH}$ range $7<\mathrm{pH}<10$, calcite is positively charged, because of the prevalence of positive ionic species. The concentration of $\mathrm{Ca}^{2+}$ singly charged hydroxo complexes $\mathrm{CaOH}^{+}$and $\mathrm{CaHCO}_{3}^{+}$reaches maximum and covered the calcite surface witch is rendered positively charged $[37,38]$.

3) Species to be considered in a system with an anionic surfactant $\mathrm{RCOOH}$ in aqueous solution in the presence of an indifferent electrolyte $\mathrm{MX}$ are $\mathrm{RCOOH}$ (undissociated acid), $\mathrm{RCOO}^{-}$(oleate anion), $\mathrm{RCOO}_{2}^{-2}$ (oleate dimer), $(\mathrm{RCOO})_{2} \mathrm{H}^{-}$(ionomolecular 
dimer), $\mathrm{M}^{+}, \mathrm{X}^{-}, \mathrm{H}^{+}$, and $\mathrm{H}_{2} \mathrm{O}$. It may be noted that in the basic region the contribution of species such as $\mathrm{RCOO}^{-}, \mathrm{RCOO}_{2}^{-2},(\mathrm{RCOO})_{2} \mathrm{H}^{-}$are maximum [39].

4) PVA chains contain acetate $\left(-\mathrm{C}_{4} \mathrm{H}_{6} \mathrm{O}_{2}-\right)$ groups and hydroxyl -OH groups which did not undergo hydrolysis. An electrostatic interaction forces via hydrogen bonding betwen these functionals groups and $\left(-\mathrm{CH}, \mathrm{RCOO}^{-}\right)$group from sodium oleate occurs.

In this condition, chemical interaction between surfactant and mineral occur. The negative oleate are bonded to the positively ions charged surface and this leads to the monocoordinated surface (calcium oleate RCOO-Ca ${ }^{+}$) or bicoordinated surafce (calcium dioleate RCOO-Ca-OOCR). After these complexe formation onto calcite surface coadsorption of polymer (PVA) at the calcite-sodium oleate/water interface may be due to electrostatic interaction forces via hydrogen bonding between PVA functional groups (acetate $\mathrm{C}_{4} \mathrm{O}_{2} \mathrm{H}_{6}{ }^{-}$and hydroxyl, $-\mathrm{OH}$ ) and (carboxylates $\mathrm{RCOO}^{-}$and $-\mathrm{C}-\mathrm{H}$ groups) in sodium oléate. A Schematic representation of the coadsorption of a nonionic polymer on (positively charged) calcite in the presence of an anionic surfactant is given in Fig. 8. Cleverdon and Somasundaran, (1985) [40], in a similar approach, proposed a conformational scheme for the cationic polymer masking the anionic dodecylsulfonate layer on negatively charged silica.

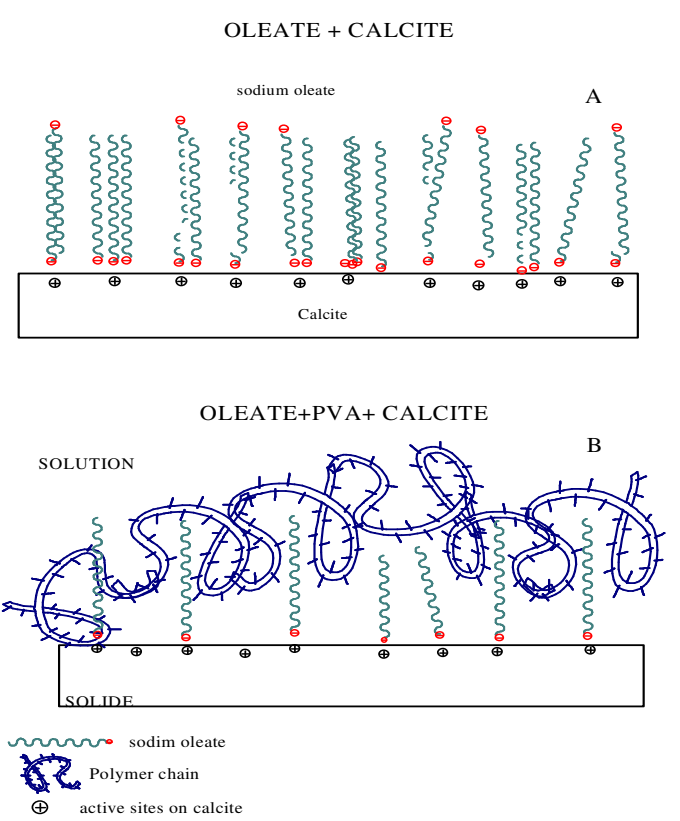

Fig. 8. Schematic representation of sodium oleate-calcite adsorption (A), and coadsorption of a surfactant (SOl) and a polymer (PVA) at the calcite/water interface (B). 


\section{CONCLUSIONS}

Results of adsorption, zeta potential meauserments, FTIR and X-Ray diffraction stuides allowed formulate following conclusions:

- Sodium oleate presence markedly influenced amount of PVA adsorbed on the surface of $\mathrm{CaCO}_{3}$. The increase of the polymer adsorption is connected with formation of polymer-surfactant complexes in water solution of PVA and sodium oleate. The same complexes are formed also on the surface of $\mathrm{CaCO}_{3}$.

- Polymer surfactant interactions lead to the change of the structure of macromolecule in the solution and at the interface alike.

- Presence of the surfactant results in a certain increase of the thickness of the adsorbed polymer layers on the surface of $\mathrm{CaCO}_{3}$.

- Molecular weight of the polymer and its concentration, are found main parameters influencing PVA adsorption onto calcite surface.

- The reaction between oleate anions and calcite is a chemical type. The interaction between oleate anions and PVA is a physical type (via hydrogen bonding).

\section{REFERENCE}

[1] Starov, V. M., Serguei R. K.; and Manuel, G. Velardey., 2000, J. Colloid Interface Sci, 227, 185-190.

[2] Emil, J., and Chibowski, S., 2005 Surface free energy and wettability of silyl layers on silicon determined from contact angle hysteresis, Advances in Colloid and Interface Science, 30, 121-131.

[3] Bajpai, A.K., and Vishwakarma, N., 2003, Colloids and surfaces, A:

Physicochemical and Engineering Aspects, 220, 117-130.

[4] Killmann, E., Maier, H., Baker, J.A., (1988), Hydrodynamic layer thickness of various adsorbed polymers on precipitated silica and polystyrene latex, Colloids Surf, 31, $51-71$

[5] Chibowski, S., Paszkiewicz, M., 2001, Studies of the influence of acetate groups from polyvinyl alcohol on adsorption and electrochemical properties of the $\mathrm{TiO}_{2}$-polymer solution interface, J. Dispers. Sci. Technol, 22, 281-289. 
[6] Boisvert, J.P., Persello, J., Guyard, A., 2003, Influence of the surface chemistry on the structural and mechanical properties of silica-polymer composites, J.Polym. Sci, Part B : Polym. Phys, 41, 3127-3138.

[7] Rachas, I., Tadros, T. F., Taylor, P., 2000, The displacement of adsorbed polymer from silica surfaces by the addition of a nonionic surfactant, Colloids Surf, A:

Physicochem. Eng. Aspects 161, 307-319.

[8] Pattanayek, S.K., Juvekar, V.A., 2002, Prediction of adsorption of nonionic polymers from aqueous solutions to solid surfaces, Macromolecules 35, 9574-9585.

[9] Gibson, F.W., Davis, R.M., Riffle, J.S., 1997, Adsorption ofwater-soluble polymers on submicron oxide particles, Polym. Preprints, 38 642-643.

[10] Chibowski, S., 1996, Investigation of the mechanism of polymer adsorption on a metal oxide/water solution interface, Adsorp. Sci. Technol, 14, 179-188.

[11] Meiron, T.S., Marmur, A., Saguy, I.S., 2004, J. Colloid Interf. Sci, 27,437-644.

[12] Otsuka, H., and Esumi, K., 1994, Langmuir, 10, 45.

[13] Cosgrove, T., Mears, S. J., Obey, T., Thompson, L., and Wesley, R. D., 1999,Colloids Surf, 149, 329-338 .

[14] Kilau, H. W., and Voltz, J. I., 1991, Colloids Surf, 57, 17.

[15] Fleming, B. D., Wanless, E. J., and Biggs, S., 1999, Langmuir 15, 8719.

[16] Pritchard, J.G., Akintola, D.A., 1972, Talanta. $19,877$.

[17] bren, C., Cleeg, F.,.Hughes T.L., and Yarwood,J., 2000, Langmuir, 16,6488-6656.

[18] Rdziviolava, I.S., Ovchinnikova, G.P., Artemenko, S.E., Dmitrienko, T.G., 2004, Study of the thikness of polymer adsorption layerson the fibre surface, Fibre Chemistry, 36(2), 139-140.

[19] Moulin, P., Roques, H., 2003, Zeta potential measurement of calcium carbonate, Journal of Colloid and Interface Science, 261, 115-126.

[20] Koopal, L., Hlady, V., Lyklema, J., 1988, Electrophoretic study of polymer adsorption: Dextrin, polyethylene oxide and polyvinyl alcohol on silver iodide, Journal of Colloids and Interface Science, 121 (1), 49-62.

[21] M'pandou, A., Siffert, B., 1987, Polyethylene glycol adsorption at $\mathrm{TiO}_{2} / \mathrm{H}_{2} \mathrm{O}$ interface:Distortion of ionic structure and shear plane position,Colloids and Surfaces,24,159-172.

[22] Baran, A.A., Kocherga, I.I., Solomentseva, I.M., 1984, Ukr. Khim. Zhurn. 50, 1162. [23] Somasundaran, P.,Zhang,L.,2006,Journal of Petroleum Science and Engineering, $52,98-212$.

[24] Owen, A.T.,Fawell, P.D., Swiftand, JD., Farraow,J.B., 2002,Int.J.Mineral Processing,67,1-4.

[25] Chibowski, S., Paszkiewicz, M., Krupa, M., 2000, Investigation of the influence of the polyvinyl alcohol adsorption on the electrical properties of $\mathrm{Al}_{2} \mathrm{O}_{3}$-solution interface, thickness of the adsorption layers of PVA, Powder Technology, 107 (3), 251-255. 
[26] Chibowski, E., Opala, M., and Patkowski, J., 2005, Influence of the ionic strength on the adsorption properties of the system dispersed aluminium oxide-polyacrylic acid, Materials Chemistry and Physics, 93, 262-271.

[27] Nakamoto, K., 1986, Infrared and Raman Spectra of Inorganic and Coordination Compounds, New York: Wiley-Interscience, p24, 4th ed.

[28] Legodi, M.A., Dewaal, D., Potgieter, J.H., 2001, Appl. Spectrosc, 55, 361.

[29] Kumar, V., and Raju, G.B., 2002, Adsorption of oleic acid at sillimanite/water interface, Journal of colloid and Interface Science, 247, 275-281.

[30] Young, C.A., Miller, J.D., 2000, Int. J. Miner, Process, 58, 331-350.

[31] Wang, T., Turhan, M., Gunasekaran, S., 2004, Polym. Int,53, 911.

[32] Daifullah, A.A.M., Girgis, B.S., and Gad, H.M.H., 2003, Utilization of agro-residues (rice husk) in small waste water treatment plans, Materials Letters, 57, 1723-1731. [33] Bajpai, A.K., Vishwakarma, N., 2003, Adsorption of polyvinylalcohol onto Fuller's earth surfaces, Colloids and Surfaces, A: Physicochem. Eng. Aspects, 220 117-130. [34] Pattanayek, S.K., Juvekar, V.A., 2002, Prediction of adsorption of nonionic polymers from aqueous solutions to solid surfaces, Macromolecules, 35, 9574-9585.

[35] Besra, L., Sengupta, D. K., Roy, S. K., and Ay, P., 2003, Influence of surfactants on flocculation and dewatering of kaolin suspensions by cationic polyacrylamide (PAM-C) flocculant, Separation and Purification Technology,30, 251-264.

[36] Santhiya, D., Subramanian, S., Natarajan, K. A., and Malghan, S. G.,1999,Surface Chemical Studies on the Competitive Adsorption of Poly (acrylic acid) and Poly (vinyl alcohol) onto Alumina, Journal of Colloid and Interface Science, 216,143-153.

[37] Suzuki, F., Nakane, K., and Piao, J.S., 1996, J.Mater.Sci, 31, 1335.

[38] Somasundaran, P., Amankonah, J. O., and Ananthapadmabhan, K.P., 1985, Mineralsolution equilibria in sparingly soluble Mineral systems, Colloids and Surfaces, 15, 309333.

[39] Vdovič, N., and Biśgdanč, J., 1998, Electrokinetics of natural and synthetic calcite suspensions, Colloids and Surfaces, A: Physicochemical and Engineering Aspects, 137, 7-14.

[40] Cleverdon, J., Somasundaran, P., 1985, A study of polymer/surfactant interaction at the mineral/solution interface, Miner.Metall. Process, 2,231. 